\title{
"Collaboration" as a mechanism for implementation of the technological revolution in the operating processes of railway transport
}

\author{
Konstantin Komarov ${ }^{1, *}$ \\ ${ }^{1}$ Siberian Transport University, Dusi Kovalchuk st., 191, 630049, Novosibirsk, Russia
}

\begin{abstract}
This paper discusses the experience of the collaboration of five Russian railways in Siberia and the Far East, four universities of railway transport, and ten laboratories of the Siberian Branch of the Russian Academy of Sciences. The activity of the collaboration was carried out as a part of the Program of Scientific and Technical Cooperation of Railways, Universities of Ministry of Railways in the regions of Siberia and the Far East, and the Siberian Branch of the Russian Academy of Sciences. The program was approved by the Minister of Railways of the Russian Federation and the Chairman of the Siberian Branch of the Russian Academy of Sciences. Within the framework of the activity of this one of the first collaborations for railways in Russia, sets of technical, technological, project documentation and application software packages were developed; and also specialized sites for diagnostics and repair of the track were equipped. The program showed its effectiveness, and the obtained results were recommended for implementation on all railways of the country.
\end{abstract}

\section{Introduction}

Now in the world there is a change in the system of higher education because of the transition to a new technological paradigm. In particular, this is due to the correction of the system of state funding for higher education, the change in the status of professors, the change in corporate culture, and some simplification of the requirements for the quality of education. To some extent, this also applies to the post-Soviet higher school: the volume of domestic expenditures on $R \& D$ has decreased for two decades; also, the number of scientific institutes and design bureaus of testing stations has decreased. Accordingly, in the field of fundamental and applied research, the number of researchers, whose number in the USSR reached 1.5 million, has decreased significantly. Under these conditions, various kinds of collaborations began to be formed, including in the form of "crowdfunding".

Currently, there is a transition to a new stage of the technological revolution, the main tool of which is the intellectual analysis of data. One of the leaders of such an important activity for Russia as railway transport, the first deputy of general director of JSC "Russian Railways" A.A. Krasnoshchek speaks about the importance of using the Big Date and

\footnotetext{
*Corresponding author: komarovk12015@gmail.com
} 
Internet technologies in the industry. Such an assessment should first of all set up systems that reproduce the human and scientific potential of the industry. The system of higher education plays a major role in the formation of the intellectual potential of the national economy for each technological paradigm.

\section{Methods of research}

It should be kept in mind that even in one of the most developed countries of the modern world - the USA, according to some experts, the importance of higher education was reduced in five ways $[1,2,3]$.

1. Elimination of the financing of public higher education.

2. Deprofessionalisation and impoverishment of professors.

3. Introduction of a class of managers/administrators who seize control of universities.

4. Introduction of corporate culture and corporate finance, leading to a change in the mission of the university.

5. Simplification and destruction of the quality of education, associated with the use of all kinds of tests instead of the ability to learn to think, raise questions, and defend a decision.

To some extent, some of these problems also occur in the post-Soviet higher school. According to the published data $[3,4,5]$, the USSR was among the world leaders by the volume of domestic expenditure on R \& D, which reached 5\% of GDP. Almost 1.5 million researchers worked in the field of fundamental and applied research, i.e. about one quarter of all scientists in the world. At the same time, industrial science was represented by about 5 thousand institutes, design bureaus, and testing stations. In two decades (from 1992 to 2011), the number of research organizations in the Russian Federation has decreased by almost $20 \%$, and the number of design bureaus has decreased in 2.4 times [2].

\section{Results}

In these conditions, a kind of "collaborations" began to be formed (in English, collaboration means cooperation). By definition, "crowdfunding" can be attributed to the collaboration. Such systems usually work in trade, project management, publishing, and music. But from the point of view of the question under consideration, the possibilities of collaboration in education and science are of interest. As an example that confirms the benefits of collaboration in Russia, one can cite the experience of the Siberian State Transport University, which in 2000-2003 initiated and directed the "Program of Scientific and Technical Cooperation of Railways, Universities of the Ministry of Railways in the regions of Siberia and the Far East, and the Siberian Branch of the Russian Academy of Sciences" [6]. It was one of the first collaborations in Russia. During its work, following were developed for the railways of the Russian Federation:

- 280 sets of technical, technological, design, and other documentation (instructions, methodologies, technical passports, etc.);

- 162 packages of application programs;

- equipped more than 110 specialized sites for diagnostics and repair of the track.

Several dozens of developments implemented during the Program were recommended for implementation on all railways of the country. The program operated until 2004 and showed the effectiveness of cooperation between enterprises and organizations of academic and university science. Thus, long before the formation of the collaboration model, such model was already used to train specialists and for scientific and technical development of railway transport enterprises, at which about 400 thousand people worked at that time. 
The collaboration included:

- Siberian State Transport University (SSTU),

- Far Eastern State Transport University (FESTU),

- Irkutsk State University of Railway Engineering (IrSURE),

- Omsk State Transport University (OmSTU),

- 10 laboratories of institutes of the Siberian Branch of the Russian Academy of Sciences.

The Program was directed by the Council of Chief Engineers of the five railways participating in the Program (South Ural, West Siberian, Krasnoyarsk, East Siberian and Far Eastern) [6].

Today, "Digital Railroad" concept is implemented in JSC "RZD", which is a whole complex of technological management tools. The basic elements of the Concept are guided by the transition to a digital description of objects, their continuous monitoring, the use of a set of centralized computational tools, including mobile systems of personnel. Important fact is that a customer-oriented approach is declared a key problem in the Concept. For the holding, which has more than 30 types of business in its portfolio - from freight and passenger transportation and logistics to construction, design, IT-technologies, and even healthcare services, it is a cardinal reversal of all resources towards satisfying the client's interests as a priority task.

To obtain a synergistic effect, a vertical management system for customer-oriented development of activities in all areas of the holding's operation is developed in JSC "RZD". Client-oriented approach in the sphere of passenger transportation is, in particular, the differentiation of the ticket costs, the development of loyalty programs, online sales. In the sphere of passenger transportation, the use of dynamic pricing methods, marketing initiatives, the increase in the number and directions of high-speed long-distance trains, and some other measures will contribute to the increase of the carrier's income.

Concerning one of the main problems of the "Digital Railway" project, First Deputy of general director of JSC "NIIAS" Rosenberg E.N. called the basic elements [7]:

- building of digital models of infrastructure facilities in a single coordinate and time space;

- creation of digital communication networks based on satellite communications of high precision positioning;

- provision of continuous monitoring of infrastructure facilities;

- organization of monitoring the condition of the rolling stock with the possibility of predicting the residual operation time;

- provision of full automation of individual technological operations;

- the use of mobile means to monitor the location of personnel and its psychological state.

If we talk about the goal of a new customer-oriented approach in JSC "RZD" in such key businesses as freight transportation and logistics, it is the attraction of cargo volumes from other modes of transport, primarily high-margin ones, due to the formation of new logistics products.

Client-oriented approach in the sphere of passenger transportation is the differentiated cost of tickets, the development of a loyalty program, online sales. To this we must add an increase in comfort, speed, safety, and the offer of modern services. Talking about questions outlined at the beginning of this work, in particular about the experience of scientific and technical cooperation between the railways of Siberia and the Far East, academic and university science, it is of interest to expand and consolidate this form of cooperation in the form of "collaboration". This form of cooperation involves the temporary alliance of specialists and organizations to achieve a specific common goal. 
Analysis of the documents defining the strategic perspectives of the technological development of railway transport in the world, such as "Global Vision of Railway Transport Development" (GVRTD), the materials of the International Council for Railway Research, "Objectives-2050: The Vision of the railway center and the technical strategy for the development of the European railway industry of the future" (VIC, 2014) shows that the key trends in the development of the railway industry, along with innovative energy and resource efficient systems for rolling stock and infrastructure, is the creation of a "smart railway". In the opinion of the former first vice-president of JSC "RZD" V.N. Morozov, the need to create such system is dictated by the strategic tasks facing the company. If we talk about customer-oriented approach, then, according to V.N. Morozov, the concept of "customer-oriented approach" includes not only the external component, but also the effective interaction between business units and divisions within the company. Examples of railways in Germany and Finland show that they provide a variety of services aiming to ensure the fast and more financially efficient transportation. Such interactions can also take place in the context of transport interaction between countries. On May 8, 2015, the President of the Russian Federation V.V. Putin and President of the People's Republic of China Xi Jinping adopted a joint statement on cooperation in combining the construction of the Eurasian Economic Union and the "Silk Road Economic Belt". For the transport sector, this means the possibility of combining the Russian mega-project of the Trans-Eurasian belt "Development" (TEBD) with the Chinese initiative to create a fundamentally new format for Euro-Asian relations. In the future, the solution of this task will promote the introduction to a new quality level of transportation between China and Asian countries on the one hand, and European countries on the other.

\section{Conclusions}

With such perspectives, the importance of collaboration in the process of development and implementation of local, regional, national, and international transport projects significantly increases. The role of universities in future collaborations is also growing, since none of the transport or project companies, or any management center can contain personnel possessing a wide range of necessary competencies: from purely professional ones, such as locomotives, cars, track, track facilities, to such as IT systems, geoinformatics, telecommunications, business process modeling, personnel management, foreign languages, service, customs, etc.

In such conditions, the collaboration of transport organizations and universities seems to be absolutely necessary. In this context, local collaborations within national and international transport corridors and hubs, in which different types of transport, warehouses, service, primary commodities, industrial, commercial and other transportrelated companies interact, are equally useful [1].

The development of effective interaction of elements within the framework of local, regional, national, and international collaborations can significantly reduce the cost of transported products by optimizing the distribution processes.

It is especially important for our country, since the transport load on GDP per unit of output in Russia is 4.6 times higher than in the USA, and 10 times higher than in Germany. According to the World Bank, Russia currently ranks 95th in the development of logistics services. It seems rational to use the system of development and support of solving transport problems through the interaction of collaborations of different levels (interstate, state (RF), regional). An example of the regional collaboration activity is a collaboration consisting of four railways, four universities, and several laboratories of the Siberian Branch of the Russian Academy of Sciences. This collaboration was a part of the abovementioned Program of Scientific and Technical Cooperation of Railways, Universities, and 
SB RAS. As an example of a local collaboration, one can specify a variant of a multimodal collaboration, such as the Novosibirsk Multimodal Transport Hub (NMTH) [1]. If we talk about the "quantum" of the collaboration by one of the universities, for example, SSTU, then this "quantum" can be formed as a part of a group of departments and laboratories that have never worked within the framework of one project outside such an organization.

In SSTU, for example, they may include such departments as:

- Management of operational work;

- Railway stations and hubs;

- Research, design and construction of railways and highways;

- Logistics, commercial work and rolling stock;

- Management in transport;

- Rail transport operation;

- Bridges;

- Tunnels and subways;

- Accounting and audit in railway transport;

- Life safety;

- System analysis and project management;

- Foreign language;

- Customs;

- World economy and tourism, and others.

The list of attracted specialists can be expanded at the expense of research laboratories and scientific and engineering centers.

There is no such wide range of competencies for any industrial research institute. However, it is necessary to control the collaboration from one center and such a center should be one of the leading scientific research institutes - VNIIZhT (Railway Research Institute) or NIIAS (Research and Design Institute for Information Technology, Signalling and Telecommunications in Railway Transportation). Using this approach, it is possible to form a highly professional geographically-distributed periodic management system without significant material costs.

The activities of the collaborations within the universities of the railways, as well as in conjunction with the railways of the respective regions, will facilitate the implementation of the technological revolution in transport, and also contribute to the strengthening of the professional training of future transport specialists.

\section{References}

1. K.L. Komarov, Novosibirsk multimodal transport hub (Publishing house of SSTU, Novosibirsk, 2001)

2. A. Mechanic, Expert 36(955), 48-53 (2015)

3. K.L. Komarov, L.K. Komarova, Alma Mater, Bulletin of the Higher School 1, 89-95 (2016)

4. How the higher education in the USA was destroyed in five ways, http://www.russiapost.su/archives/65380

5. S.M. Rogov, RF: science and R\&D. Extract from the report, 69100.livejournal.com/1875749.html

6. K.L. Komarov, Bulletin of the Program of Scientific and Technical Cooperation of Railways and Universities of the Ministry of Railways of Russia in the regions of Siberia and the Far East, 3-8 (2003)

7. E.N. Rosenberg, Automation, Communication, Computer Science 10, 4-5 (2016) 